\title{
SOME GROWTH PROPERTIES OF WRONSKIANS USING THEIR RELATIVE ORDER
}

\author{
SAnJib Kumar DatTa, Tanmay Biswas and Sultan Ali
}

Abstract. In the paper we establish some newly developed results based on the growth properties of relative order, relative type and relative weak type of wronskians generated by entire and meromorphic functions.

Mathematics subject classification (2010): 30D20, 30D30, 30D35.

Keywords and phrases: Entire function, meromorphic function, relative order (relative lower order), relative type (relative lower type), relative weak type, wronskian.

\section{REFERENCES}

[1] S. K. DatTA And A. JHA, On the weak type of meromorphic functions, Int. Math. Forum, Vol. 4, No. 12 (2009), pp. 569-579.

[2] S. K. DATTA AND AND A. BISWAS, On relative type of entire and meromorphic functions, Advances in Applied Mathematical Analysis, Vol. 8, No. 2 (2013), pp. 63-75.

[3] W. K. Hayman, Meromorphic Functions, The Clarendon Press, Oxford, 1964.

[4] B. K. LAhiRi AND D. BANeRJEe, Relative order of entire and meromorphic functions, Proc. Nat. Acad. Sci. India, Vol. 69 (A) III (1999), pp. 339-354.

[5] I. LAhiRi AND A. BANerJeE, Value distribution of a Wronskian, Portugaliae Mathematica, Vol. 61 Fasc. 2 (2004), Nova Série, pp. 161-175.

[6] G. VAliron, Lectures on the general theory of integral functions, Chelsea Publishing Company, 1949. 